\title{
Learners' Perceptions of the Use of Mobile Technology in a Task-Based Language Teaching Experience
}

\author{
Simone L. Calabrich ${ }^{1}$ \\ ${ }^{1}$ King's College London, London, United Kingdom \\ Correspondence: Simone L. Calabrich, King's College London, London, United Kingdom. E-mail: \\ calabrich.simone@gmail.com
}

Received: April 13, 2016

doi:10.5539/ies.v9n12p120
Accepted: July 6, $2016 \quad$ Online Published: November 24, 2016

URL: http://dx.doi.org/10.5539/ies.v9n12p120

\begin{abstract}
This research explored perceptions of learners studying English in private language schools regarding the use of mobile technology to support language learning. Learners were first exposed to both a mobile assisted and a mobile unassisted language learning experience, and then asked to express their thoughts on the incorporation of mobile devices into the language classroom. The mobile assisted tasks involved learners posting a review online based on a real past experience, as well as using web-search engines to gather enough information to plan a hypothetical trip. Findings revealed overall positive attitudes amongst the students surveyed. Arguments in favour of the incorporation of mobile technology in the language classroom included: the possibility of having access to a range of materials superior in both quality and quantity when using mobile devices to access the Internet, among others. However, a significant amount of scepticism towards Mobile Assisted Language Learning emerged. Arguments against suggested that the format of presentation, rather than the type of task, seemed to constitute a motivational factor that played a psychologically significant role to some of the learners.
\end{abstract}

Keywords: authentic materials, mobile assisted language learning, task-based language teaching

\section{Mobile Assisted Language Learning in Task-Based Language Teaching}

\subsection{An Overview of Mobile Assisted Language Learning}

Mobile technology seems to have pervaded virtually every single aspect of daily life. Not surprisingly, due to their convenient portability and connectivity, mobile devices, with their ever-expanding multi-functional nature, have also made their way to the language classroom, be it as a distraction to students who seem to be constantly checking their social networks and surreptitiously exchanging messages with their peers, or as a pedagogical tool, affording learners a wide range of applications and web-resources at the convenience of their fingertips.

Mobile Assisted Language Learning (MALL henceforth) has existed for nearly two decades now (Burston, 2014). According to Kukulska-Hulme and Shield (2007), the term refers to formal or informal language learning mediated via handheld devices, such as mobile phones, tablets and laptops, available anytime, anywhere, or, as succinctly put by Trifonova et al. (2004), "...any device that is small, autonomous and unobtrusive enough to accompany us in every moment". To Martin and Ertzberger (2013), mobile devices can provide language learners with a wide range of opportunities to scaffold learning both inside and outside the classroom whenever needed. Kukulska-Hulme (2009) posits that, if encouraged to use their personal devices in class, students are likely to engage in follow-up learning spontaneously, particularly when their motivation is high (Petersen et al. 2009), taking learning out of the realms of the classroom, which, as noted by Miangah and Nezarat (2012), makes education as ubiquitous as possible. Chinnery (2009) highlights that one of the conveniences of the widespread ownership of mobile devices is that activities supported by technology can be easily integrated into the class without having to move students to computer labs, which in some schools are either limited or non-existent.

\subsection{Principles and Practice}

A quick search on mobile app stores yields hundreds of language learning applications, such as phrasebooks and flash cards. Most of these applications, however, lack an explicit theoretical foundation as observed by Burston (2014), which, according to Zilber (2013), may be explained by the fact that a great number of app developers have a very superficial understanding of language teaching methods. Duolingo, for example, one of the most 
popular language learning apps currently available, in which learners supposedly gain fluency whilst translating real-world sentences, fails methodologically, in Garcia's (2013) view, by not drawing its vocabulary learning activities upon corpus linguistics research, completely disregarding issues such as word frequencies. Zilber (2013) suggests that even seemingly reputable publishers of language learning materials have failed to produce high quality apps since many of them simply digitize their textbook content, often with minimal adaptation, utterly disregarding the high levels of interactivity and web-connectivity that mobile devices allow, and commercialize them as mobile apps to be used in the language classroom.

Though MALL has the potential to support collaborative task-based learning (A. Herrington \& J. Herrington 2007; Kukulska-Hulme \& Shield, 2007), the emphasis given in MALL has been mainly on content delivery, within an implicit behaviourist transmission-model framework, and following a teacher-centred language pedagogy (A. Herrington \& J. Herrington 2007; Burston, 2011). Early generations of MALL, in particular, tended to focus on working with text messaging for vocabulary learning, grammar quizzes and surveys (Kukulska-Hulme \& Shield, 2007) placing the learner at the receiving end of instruction, and emphasizing the passiveness "expected" from students in language teaching approaches prior to Communicative Language Teaching. A. Herrington and J. Herrington (2007) deem such educational use of mobile devices as limited and pedagogically regressive. To them, educators seem to follow a typical pattern of reverting to old pedagogies when using new technologies, and propose instead that more recent theories of language learning be adopted when devising MALL materials and tasks.

Khazaie and Ketabi (2011) also urge educators to move from a view of MALL as a solely delivery mechanism of content, and fully exploit its potentials. One of such potentials, according to Fotouhi-Ghazvini et al. (2009), is that MALL tasks can place learners at the centre of instruction where the role played by the teacher becomes facilitative rather than instructional. To Ally and Santos (in: Ally, 2013), one way of exploiting mobile technology in education is by developing tasks that encourage production of student-generated content online. An example of a MALL task which encouraged students to contribute actively to their language learning can be found in a study conducted by Kim et al. (2013), in which students were assigned presentations that required them to create videos to be shared on YouTube. Activities as such, in Herrington and Herrington's (2007) view, "refocus the energy for learning on the student" who then becomes the "generator of knowledge". Comas-Quinn et al. (2009) warn teachers that this type of activity may, in contrast, result in students feeling sceptical for having been requested to work in seemingly unfamiliar ways if they are not used to taking the lead in the classroom.

\subsection{Assuming Control}

Fearing that their students are more technology-competent than themselves (A. Herrington \& J. Herrington, 2007), some teachers might feel self-conscious and assume they are not technologically prepared to devise MALL tasks. However, as pointed out by Burston (2011), "technology can only be as good as the pedagogy behind it" (p.4). Therefore, a simple, but theoretically sound, guided Internet exploration to be conducted from students' devices, could be much more beneficial than a superficially developed, methodologically speaking, language learning app. By exploring the Internet from their devices whilst carrying out inquire-oriented activities, learners can have access to amounts of information that extend thousands of times beyond their instructor's potential knowledge base (Bonk \& Cummings, 1998), affording a much wider scope than any materials brought to class in printed format. Knowing how to find their way through all this ever-increasing amount of information constitutes what Brown (2006) calls navigationism. In a navigationist learning paradigm, learners should be able to "find, identify, manipulate and evaluate information" in order to best assimilate it and integrate it into their lives accordingly (ibid).

While some could argue that, when undertaking language tasks which involve web-based inquiries, learners could just as easily use the school desktop computers, Kukulska-Hulme (2009) considers ownership of the mobile device to be of the utmost importance by suggesting that a technological tool that has only been borrowed may not be as empowering as one that is owned and with which students are very familiar. Miangah and Nezarat (2012) believe that, when using their own devices, students are given higher control of the learning process. Notwithstanding, although MALL enables learners to "lead at least some of the way" in their language learning path, as pointed out by Kukulska-Hulme (2009), it is advisable that learners be coached accordingly, as advocated by proponents of navigationism (Brown, 2006). To this end, McGrath (2002) recommends that students be given a pre-selected list of options (e.g. links to various webpages) to choose from, especially because some might feel overwhelmed for having to choose materials from a virtually infinite array of resources. However, in order to ensure students are assuming control over their own learning, he believes it to be paramount to give students the freedom to select whichever materials they find appropriate and relevant to their 
needs, allowing learners to choose their own learning paths (Stoks, 2002; Kukulska-Hulme et al., 2015).

\subsection{Links to the Real World and Task Based Language Teaching}

Godwin-Jones (2011) comments on how learning becomes more real and permanent when we manage to tie it to students' lives outside the classroom. Tying language learning activities performed in class to the outside world has been a goal for many language educators ever since the emergence of Task Based Language Teaching (TBLT henceforth). Skehan (1996) conceptualizes TBLT as the approach in which meaning should be a primary goal in the tasks proposed and one in which there must be a real world relationship. To Godwin-Jones (2011), chances of achieving the goals of TBLT are enhanced when we encourage learners to use mobile technology in class. The interdependence between technology and TBLT, touched upon by Doughty and Long (2003), summarized in: Lai and $\mathrm{Li}$ (2013): "technology provides a natural and authentic venue for the realization of the methodological principles of TBLT" (p. 499).

\subsubsection{Authenticity in Task Based Language Teaching}

Along with real-world situations often come real-world materials, or, as generally referred to in the literature, authentic materials. Authentic materials (AM henceforth) have been defined by Nunan as any material which has not been produced for the purposes of language learning/teaching (1989), in the course of genuine communication (1999), and which may have been produced by first or second language users (Badger \& MacDonald, 2010). To McGrath (2002), the fewer authentic samples of language learners are exposed to, the less well prepared they will be for the real world because, as suggested by Bahrani and Shu Sim (2013), AM have the potential to assist learners in noticing the immediate relevance of what is done in class to what they need to perform linguistically in the world outside the classroom setting. Exposure to authentic samples can be enhanced through the web-connectivity inherent to modern mobile technology, which affords teachers and learners easy access to unlimited sources of authentic content (Chinnery, 2009), meaning that language learning materials no longer need to be dependent upon institutional resources (Stockwell, 2007), and can now be easily retrieved by learners themselves. It is noteworthy, though, that providing learners with AM without careful selection may raise learners' anxiety if they are not cognitively ready to comprehend the language they are being exposed to (Nunan, 1989). Furthermore, the randomness of vocabulary and structures encountered in some samples of language may not cover the range of features that are directly relevant to learners' current cognitive state (Gallien, 1998).

Similarly, authenticity of the task should be as important as the authenticity of the text (Guariento \& Morley, 2001; Stoks, 2002). Stoks (2002) advocates for language learning tasks to be realistic and functional, while Guariento and Morley (2001) identify as one of the crucial aspects of task authenticity whether a genuine purpose has been the target of the communicative interaction. To pursue a genuine purpose, Koole (2009) proposes that the output of the MALL activities be shared with members of a real and larger community. Warschauer and Whittaker (1997) comment that the Internet creates optimal conditions for learners to develop writing skills because of the possibility of interaction with an authentic audience. In a study by Petersen et al. (2009), for example, students participating in an exchange program were encouraged to use their smartphones and tablets over the span of eleven weeks to share their views on the town they were visiting in a blog devised for the experiment. Koole (2009) believes that when students are aware that the learning task they are undertaking have a real purpose and a real audience, learner motivation increases. McGrath (2002), conversely, highlights that it is possible that learners have "different expectations of classroom activities and their real-world parallels" tending to prefer form-focused activities over communicative practice.

\subsection{Individual Preferences and Learning Styles}

Ally (2013) predicts that future generations of learners will demand that mobile technology be an inseparable facet of their educational path. A. Herrington and J. Herrington (2007), conversely, believe that younger learners may resent if their favoured technologies are expropriated by their teachers for pedagogical purposes. Rather than a generational issue, such reluctance may also be what Koole (2009) refers to as assimilation bias, i.e., "a reluctance to adopt new procedures". Ushioda (2013) recommends the use of mobile technologies in the language classroom be optional. As put by Rogers (in: Ushioda 2013), different individuals may not be equally inclined to embrace the incorporation of technologies. Ultimately, it is highly advisable that, before implementing a MALL environment, teachers check their students' technology background (Lacina, 2008), as to avoid alienating those unable to purchase mobile devices, or those with any kind of physical impairment which might prevent them from using the devices.

While educators should respect and be sensitive to individual preferences, it has been urged by APA (1997) that teachers help their students learn how to expand and modify their learning preferences whenever these are 
perceived as insufficient in assisting learners accordingly. To Fotouhi-Ghazvini et al. (2009), one of the greatest advantages of MALL is that mobile devices have the potential to conveniently accommodate and cater for different learning styles and for different groups of learners. As pointed out by Elias (2011), mobile devices allow sound, text, pictures and videos to scaffold learning. Likewise, Koole (2009) believes that access to multimedia affords learners a variety of stimuli, which should help them comprehend, and possibly, retain, concepts more effectively by reducing the cognitive load bestowed upon them. Norwood (in: Martin and Ertzberger, 2013), however, challenges this idea by claiming that the increasing presence of mobile devices in the classroom might distract students from paying attention to the lesson, which, to him, jeopardizes their ability to retain any of the information being imparted. Findings from a study conducted by Sheppard (2011) in which students used $i P a d s$ for reading tasks revealed that the use of mobile technology in class served as a distracter, hindering "offline" discussion. Nevertheless, if not encouraged to use mobile devices in class, some learners may never come to realize the full extent to which such technology can be pedagogically beneficial to them. In an investigation conducted by Woodcock et al. (2012), for instance, the participating students were initially largely unaware of how mobile devices could be used to support learning but quickly demonstrated openness once the idea was introduced to them. Similarly, drawing upon findings from their research, Demouy and Kukulska-Hulme (2010) advise that "learners need to be helped towards recognizing the specific value of practice on the mobile phone", which, to them, is a "stepping stone towards authentic communication" that not all students will acknowledge right away (p. 3).

\subsection{Some Constraints}

Some scholars question the suitability of mobile devices for activities involving lengthy written tasks due to text input methods available (Sussex, 2012; Ushioda, 2013; Burston, 2014). To Sussex (2012), mobiles are most suitable for listening, speaking and reading but have compromised capacities for writing due to the ergonomics of text input, which might impose significant constraints to users, such as slow speed of input depending upon the type of keyboard available, which, in Ushioda's (2013) view, might incite superficiality of learner engagement.

\subsection{Research Question}

As evidenced in this literature review, there is a rapidly growing body of theoretical research on mobile assisted language learning attempting to demonstrate its effectiveness. I aimed to contribute to research in the field by investigating general English learners' perceptions of this issue. The research question I proposed to guide this investigation is as follows:

What are the learners' perceptions of the use of mobile technology to support language learning in a task-based language learning experience?

As demonstrated by the research question, the focus of this research was a broad one. I preliminarily selected the four themes below to guide the investigation but kept an open-mind towards the emergence of any new themes:

- Students' satisfaction associated with the MALL experiment as a whole;

- $\quad$ Students' perceived value of mobile devices in assisting language learning in class;

- Students' perceived contribution to their own learning when using mobile technology in the language classroom;

- Students' view of task authenticity in a mobile assisted language learning experience.

\section{Methodology}

\subsection{The Experiment and the Data Collection Procedures}

\subsubsection{The Tasks}

I made an a priori assumption that a significant number of students would never have been exposed to any structured MALL tasks in the language classroom and were, therefore, likely to have a limited understanding of the topic under scrutiny. As I did not wish to collect purely subjective evidence based on unsubstantiated examples and abstract opinions, I assumed that in order to obtain informed testimonials, I should design learning materials for this investigation so as to provide students with first-hand experience with mobile-assisted tasks before collecting their perceptions.

Age limit was not set for the present research so that perceptions collected would not reflect one single age group or one given generation, but would reveal contrasts and similarities, if any, across age groups.

Two different versions of two different tasks were then created for the present study. Each task had a 
mobile-assisted version (available at http://kclmall.blogspot.co.uk/) and a non-assisted counterpart (Appendix A). The former I refer to here as MALL task, and the latter as paper-based task. The topic selected for both tasks was 'Travel'.

The blogging service which I selected to post the tasks descriptions in was Blogspot, which is a sub-domain of Blogger, a free weblog publishing tool powered by Google. The blog, though originally intended to be viewed in desktop computers, allows bloggers to offer visitors mobile-friendly templates for better user experience. At first, the idea of developing an app to include the experimental tasks was contemplated. However, since the primary focus of the MALL tasks created for this study was on the pedagogical affordances students could potentially gain from accessing authentic materials on the Internet in the language classroom from their own mobile devices, I concluded that focusing on the design of activities in a highly technological sense would be superfluous for this research as it could largely deviate from such objective.

As similarly done by Peacock (1997) in a study on authenticity, I decided not to use control groups for this investigation, but rather, to use students as their own controls. In Peacock's view, differences occurring:

among the same learners with the same teacher, doing similar activities - but with a different type of material - may be attributed to the materials in use at the time with more assurance than would be the case with differences between two classes. (p. 146)

I decided then that each student would be exposed to both a MALL task and a paper-based task as I was expecting that, by doing so, learners would more knowledgeably perceive and report how having or not having used their mobile devices had affected their learning experience in the experiment (see Figure 1).
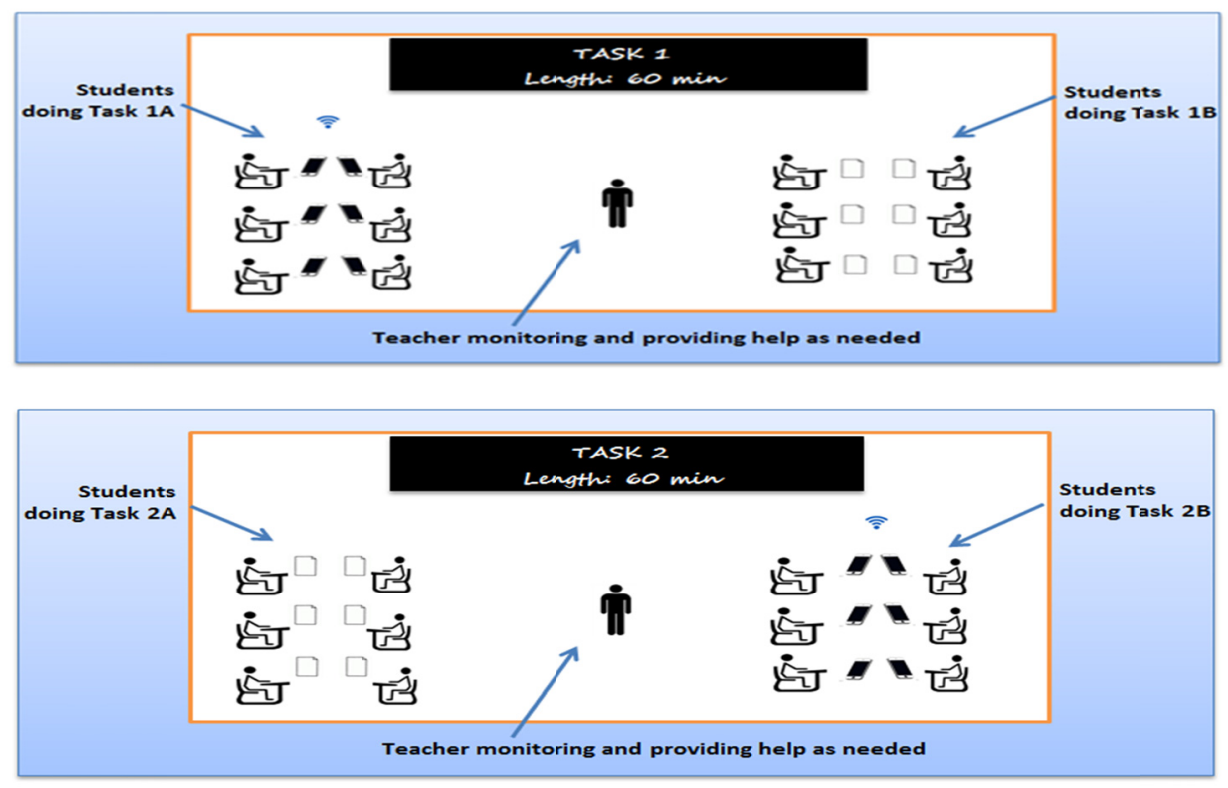

Figure 1. Models illustrating the classroom arrangement proposed in the experiment for Task 1 and Task 2

Both paper-based and MALL versions of the tasks created for this study provided students with AM from online sources. The main difference regarding the exposure learners had to AM in each task format was that, in the paper-based tasks, students received a set of printed materials extracted from the Internet by me, the researcher, whereas in the MALL tasks, students were in charge of accessing websites in order to choose and gather themselves the necessary materials for each task. Students doing the MALL tasks were given a list of suggested websites but were encouraged to use any other they judged suitable for task completion.

\subsubsection{Task 1}

In order to activate schematic knowledge, all students were requested to have a discussion in pairs about their previous travelling experiences with any type of accommodation that were somehow memorable to them. As noted by Carrell (1983), the schema theory presupposes that to best understand something, we must relate it to something we already know. 
Subsequently, students doing the paper-based tasks were given handouts containing reviews on a London-based hotel posted by Internet users. The reviews were extracted by the investigator from TripAdvisor, a website in which Internet users can post reviews of travel-related content (http://www.tripadvisor.co.uk/). Students doing the MALL tasks were instructed to use their own devices to go online and attempt to find reviews on the hotels they had discussed in pairs.

Finally, students were requested to write a review on one of the hotels they had discussed in class. Paper-based students were told to write their reviews in the handouts provided, while MALL students were told to use their mobile devices to post their reviews online on TripAdvisor, or on any other similar website of their choosing. As a result, the MALL version would provide learners with an audience beyond the limits of the language classroom, whereas the paper-based learners would only have their teachers, and possibly their classmates, as their audience. By exposing learners to such contrast, peers vs. wider audience, I intended to test, in some way, the Relate-Create-Donate philosophy, proposed by Shneiderman (1998), who suggests that learners may be motivated to higher levels of achievement upon having their output exposed to an audience beyond classmates and instructors. By doing so, I also acknowledged that some students could be reluctant to engage actively due to such public exposure of their L2 output.

\subsubsection{Task 2}

Task 2 also had a schema activation phase, where students were asked to discuss in pairs about their previous experience in planning trips. The major difference between both versions of Task 2 was that paper-based students were provided with a preset of handouts containing information on flights, sightseeing tours, and accommodation, among others, retrieved from popular travel websites, whereas MALL students were encouraged to use their mobile devices to look for the same kind of information online independently, which chimes with the ideals of the navigationism, i.e., learners acquiring skills to select information sensibly (Brown, 2006).

Planning an itinerary and presenting to classmates was the main output production requirement of both versions of Task 2. Students were free to decide how they would like to organize their itinerary following what they would generally do in a comparable real-life situation (e.g. taking notes, memorizing, taking screenshots).

\section{Findings and Discussion}

\subsection{Background Information}

The participating students $(\mathrm{N}=62)$ were recruited from 8 intact classes in 5 different private English language schools in London. Of the 62 volunteers who returned their responses to the 10-minute survey, 27 were males $(43.5 \%)$ and 35 were females $(56.5 \%)$.

Students ranged in age from 16 to 39 years old, with a mean of 25.5 and a standard deviation of 7.7. The participants came from several different countries in Europe, Middle East, South America, and Southeast Asia/East Asia, which afforded this study a diversity of cultural backgrounds and experiences.

When surveyed on their level of English, $67.7 \%$ of the students self-reported having a CEFR B2 level, whilst 29\% were $\mathrm{B} 1$ level users. Only one of the participating students had a $\mathrm{C} 1$ level, which was higher than the level originally targeted for this experiment. One of the students involved did not report their level of English.

The overwhelming majority of the students involved in this study reported owning at least one mobile device with Internet capability. $87.1 \%$ of the students reportedly have a smartphone, while $9.7 \%$ have both a tablet and a smartphone. One of the students reported having a tablet only, and one did not select any of the options provided.

$51.6 \%$ of the students reported having used a mobile device for pedagogical purposes in the language classroom prior to this experiment. However, the vast majority of the examples provided by the participants concern the use of reference functions only, such as dictionary and translation apps.

The overwhelming majority of the students $(96.8 \%)$ reported using their mobile devices to access the Internet several times a day in their everyday routine. When surveyed on what they do online on their mobiles, checking emails was reported to be performed by $82.3 \%$ of the students, sending emails by $75.8 \%$, reading the news by $67.7 \%$, text messaging by $74.2 \%$, using apps for language learning by $59.7 \%$, using dictionaries by $80.6 \%$, and reviewing products/ services by $32.3 \%$ as summarized in Figure 2: 


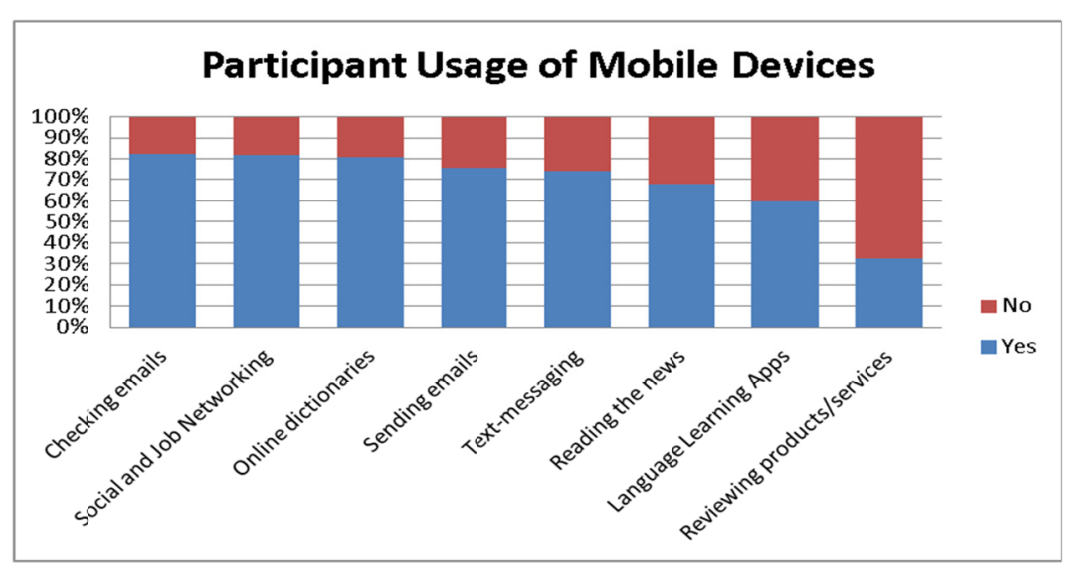

Figure 2. Participant usage of mobile devices

3.2 What Were the Learners' Perceptions of the Use of Mobile Technology to Support Language Learning in a Task-Based Experience?

\subsubsection{Perceptions per Type of Task}

Learners were randomly assigned to one of the two possible combinations of tasks as follows:

A-students: Mobile Assisted Task 1A (Posting a review online) + Mobile Unassisted Task 2A (Planning a trip using printed handouts).

B-students: Mobile Unassisted Task 1B (Writing a review on a sheet of paper) + Mobile Assisted Task 2B (Planning a trip using the Internet).

Of the 62 participants, $32(51.6 \%)$ were assigned to the A-students' group, while $30(48.4 \%)$ were assigned to the B-students' group.

$74 \%$ of all the students reportedly enjoyed the task supported by mobile technology the most. Of the 46 students who preferred doing the MALL tasks, 50\% of them were A-students, and 50\% were B-students. A slightly higher percentage difference was found among the learners who reported having enjoyed the paper-based tasks the most. $56.25 \%$ of the learners who reportedly preferred the paper-based tasks were A-students, whereas $43.75 \%$ were B-students (See Figure 3).

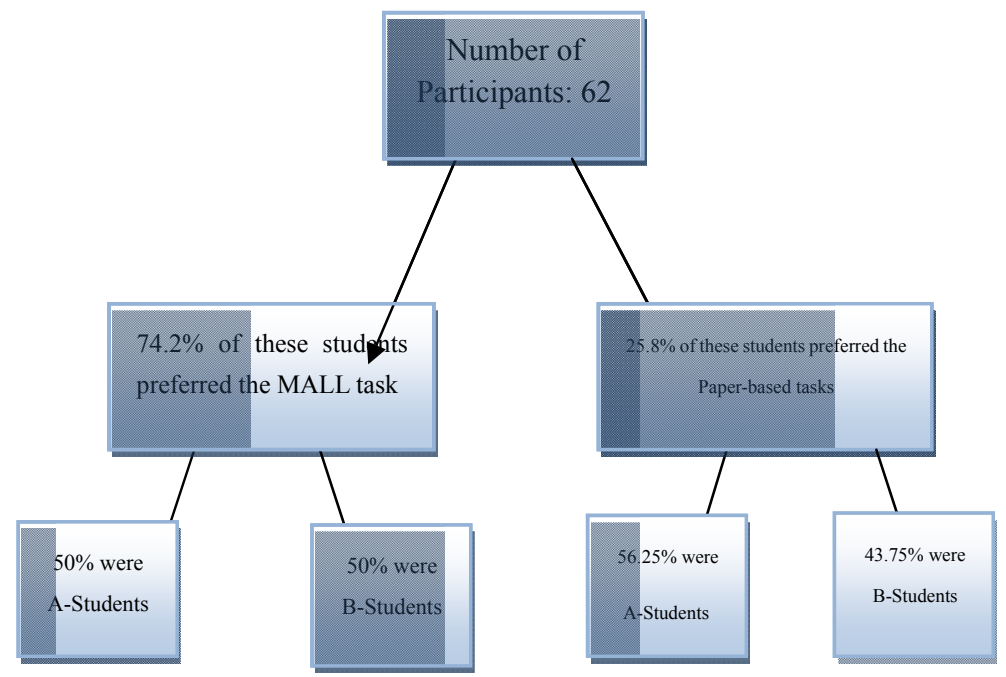

Figure 3. Students' preference per type of task 
A possible explanation as to why the percentage of A-students who preferred the paper-based task was slightly higher than the percentage of B-students may be because A-students were requested to type relatively long excerpts of texts on tiny on-screen keyboards on their phones as part of their written output production assignment, which, to some people, can be highly cumbersome, and might have possibly influenced students' perceived value of the task carried out. Such speculation, however, might not be entirely valid since over $70 \%$ of the participating students stated using their mobile devices to compose emails and text messages in their everyday lives (See Figure 2). Though not clear how lengthy their output generally is, this suggests that Task 1A should not have been deemed as an impractical or unmanageable assignment to be carried out for its text-entry requirement from an ergonomics perspective since a great number of the students are reportedly fully accustomed to typing in their devices routinely. Chinnery (2009) points out that when MALL tasks first started being developed and introduced, some hardware features typically available back then, such as smaller screen sizes, either hindered or limited the pedagogical exploitation of mobiles in class. Though screens are considerably larger now with their scrolling up/down functions, mobile text-entry can still be considered as sub-optimal by many due to the generally small keys available in virtual keyboards. While a considerable number of individuals might tolerate such sub-optimality when using their devices for personal purposes, it would be understandable if the same level of tolerance were not demonstrated when requested to use their phones and tablets for pedagogical purposes. As alerted by Ushioda (2013), some students may not necessarily feel motivated to use their personal mobile devices for language learning. Surprisingly, findings from the present study revealed that even the students who reportedly do not use their phones for typing lengthily welcomed the MALL tasks. This may be because these individuals are open to using mobile technology in other domains of their lives, or because they recognized the importance of using mobiles to assist language learning.

What could be another hypothesis as to why, comparatively, slightly more A-students than B-students preferred the paper-based tasks is that students from the former cohort may have felt that posting a review online might not be of relevance to them on a personal level. Reportedly, $75 \%$ of the A-students had never used their devices to review any products or services online in their lives prior to the experimental task they performed in this study. From this figure, it could be inferred that, because a high percentage of the A-students reportedly do not engage in reviewing products and services online routinely, asking them to perform such task in class could be deemed pedagogically irrelevant or motivationally deficient due to the alleged unlikelihood of said learners needing (or wanting) to carry this out in their lives. Nevertheless, $68.8 \%$ of all the A-students are said to be open to using mobile devices to support their language learning again in future.

Although none of the students explicitly externalized this, it is also possible that the participants who did not enjoy the mobile-assisted Task 1A as much may have felt self-conscious about having their second language learning output available online easily accessible by a wide range of individuals, especially because contributions on review websites, such as TripAdvisor, are not anonymous. If this was the case, this assumption would directly oppose both the idea proposed by Koole (2009) that having a real purpose and audience whilst engaging in a learning task may serve to increase learner motivation, as well as the Relate-Create-Donate philosophy, proposed by Shneiderman (1998), that the prospect of having a wider audience would motivate individuals in their learning path. Overall, the possibility of having their work seen as purposeful did not arise as a crucial motivational aspect in the accounts provided by the participants in the present study, which is also contrary to findings reported by Chen and Brown (2012) in their investigation of the effects of authentic audience, where such authenticity was found to increase interest among the participants involved. This issue was touched on by only one of the students in the present study, as demonstrated by her comment below:

It's very good to make a review so people can read my review then they can use it to plan when they want to go to the place that I review.

Though S3:A:5 (Sx:Y:z; where $\mathrm{S}=$ Student, $\mathrm{x}=$ Number, $\mathrm{Y}=$ MALL Task A or B, and $\mathrm{z}=$ group number), from Thailand, had never posted a review online previously, her comment above evidences that she perceived the MALL experience in a task-based language teaching task as a positive one due to her collaborating and sharing content online to benefit others. S3:A:5, who in the past had only used a mobile device in class to check for definitions and translations, realized the potential afforded by her surfing the web from her mobile, which provided her with a vast array of sources conveniently stored in her pocket. In her words:

It is good if you use mobile phone in the good way. I can get more knowledge and more information from Internet. Also, in Internet, more information than in paper.

Table 1 shows a summary of answers given by students to the closed-ended questions: 
Table 1. Closed-ended questions and answers

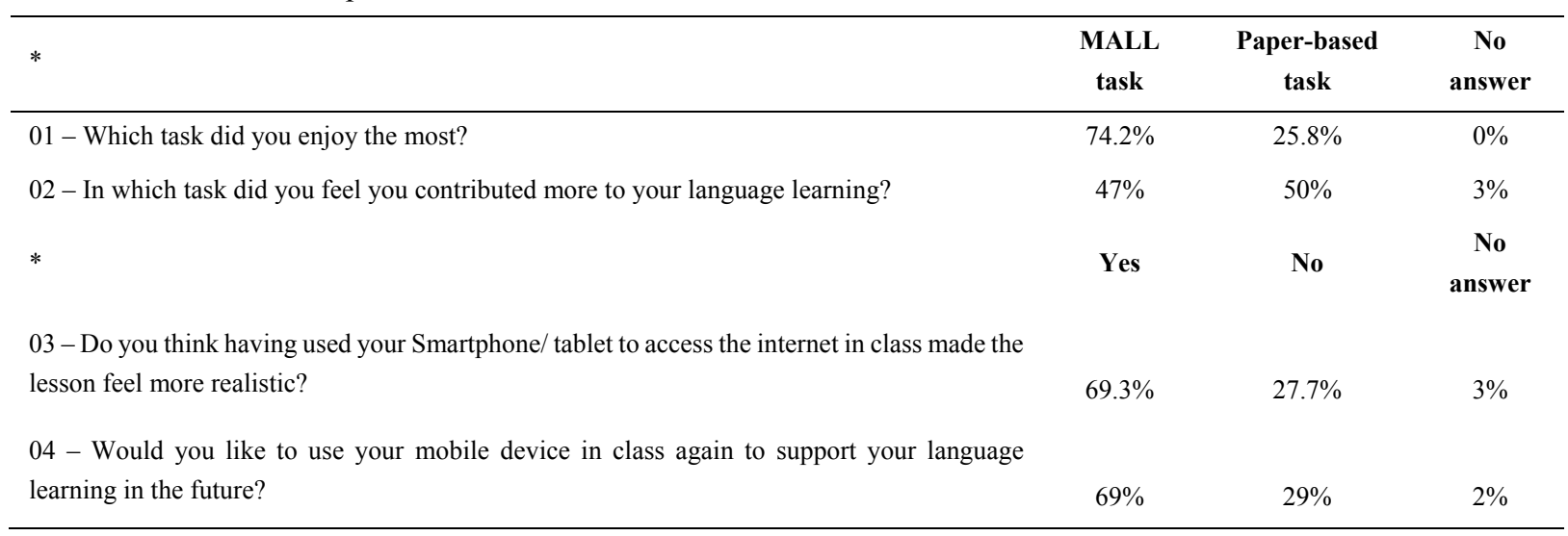

\subsubsection{Perceptions per Theme}

\subsubsection{Quantity}

The ever-increasing amount of information available online, touched on by S3:A:5 above, was also mentioned as a positive aspect associated with mobile assisted language learning by other students involved in this investigation. Most of the students who presented positive arguments regarding the volume of information online were B-students possibly because the completion of the task they had to perform required a great deal of information. S6:B:8, from Taiwan, for example, said that: "Smartphones can offer more pictures and information that paper/books can't give". Also to eight other respondents, the larger amount of information online is comparatively more beneficial, pedagogically speaking, than the inevitable limitation in scope predictably caused by printed materials. S2:A:3, for example, commented that because of the larger amount of information she had access to while using her smartphone in class, she was able to learn more lexical items, which, to her, was highly motivational.

While teachers could attempt to circumvent such limitation in scope by providing learners with additional handouts, an ecological concern has been brought into question by two students, S7:B:8 and S7:B:5 who have advocated for the use of online resources over printed materials. In S7:B:5's words:

Because the information in the internet is accurate and it has more information than the paper and no need to spend more money and the paper that we throw when we finish using it.

S7:B:5's concern chimes with Ally's (2013) reference of MALL as 'green' learning because of its reduction of use of print.

A student from Croatia (S1:B:2), mentioned that having been able to use her phone to search for input online, where information is more abundant, had played a major role in her experience by positively affecting her perceived self-contribution to her own learning:

I'd rather use my phone to my language learning and I feel that I contributed more to my language learning in that way, because I find many useful other informations on the internet, which I don't have on paper. Using the phone I learn much more.

Conversely, the abundance of information online was mentioned as a shortcoming by two students: S2:A:8, from Thailand, and S3:B:1, from Switzerland. To them, the more information available, the more overwhelming the whole learning experience can be as some of the information accessed may not necessarily be essential, which might end up leading to confusion rather than being a positive addition in a pedagogical sense. Though such concern was only touched upon by a couple of students, this suggests that care must be taken to ensure all students are provided with navigational assistance (Brown, 2006) when performing MALL tasks so as to avoid raising learners' affective filter.

\subsubsection{Quality}

The allegedly superior quality of the materials available online had as important a role as the superior quantity aforementioned, which accords with the point made by McGrath (2002) that language learners need exposure to not only a great deal of materials, but also quality materials for language acquisition to take place. Two quality-related aspects were mentioned by students as decisive determinants favouring mobile phones in class 
over printed materials: $\mathrm{a}$ - the use of mobile devices as visual scaffolding tools, and $\mathrm{b}$ - the advantage of being able to use their devices to access more up-to-date information online.

Visual scaffolding, which, to McCloskey (2005), makes language more memorable and complex ideas more accessible, is the use of visual aids to support language learning. Eleven learners mentioned that the possibility of visualizing photos and illustrations on the Internet via their mobiles whenever needed was highly advantageous as this could assist them with the clarification of meanings of words or concepts not fully understood. S9:B:4, from Thailand, for example, explicitly stated that his preference for the MALL task relates to the fact he could access the Internet to visualize pictures, which, in his view, helped him learn the lesson more efficiently. Such assistance may be of special interest to students who might have the visual learning style as their dominant one. The visualization afforded by web-based materials directly accessed from learners' own devices seemed to also appeal to eight other participants. This may be because these students are visual learners, but this was not investigated in this study. The colorfulness of photos when accessed in their original sources, as opposed to the black-and-white photocopies generally provided to students, has been associated by some of the learners, such as S5:A:5, from Colombia, and S7:B:8, from Taiwan, as a highly motivating factor to keep them interested in the materials. S2:A:3, a Polish student, has pointed out this fact straightforwardly:

Using mobile devices during lessons is much more interesting. In my case, I was definitely more into the lesson when I was using my phone. Learning new vocabulary from sheets, especially black and white copies is quite difficult for me and really not effective.

The second quality-related argument provided by learners to justify their preference for MALL tasks over paper-based ones concern the currency of information they could have access to. For these students, being exposed to samples of language from sources that are always up-to-date (allegedly) seems to play a chief role in their language learning path. S7:A:1, a Japanese student, observed that "the information [available] online is newer than textbooks", which to seven other students has also seemed to have a substantial motivational impact regarding the perceived value they attributed to the web-based resources used for pedagogical purposes in the experiment. These students seem to be willing to move towards a pedagogical incorporation of web-based

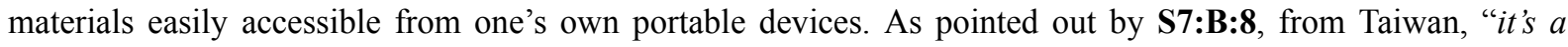
different century, [so] we need to try different things".

The idea proposed by $\mathbf{S 7 : B : 8}$ above does not seem to be shared by at least $43.5 \%$ of the participating students, whose comments conveyed a sense of scepticism towards mobile assisted language learning. Some students, like S7:A:1, admitted having enjoyed the MALL task this time but would rather not use mobile technology in the language classroom in the future. Some of the participants still have reservations about introducing mobile technology to the language classroom as illustrated by responses given to the open-ended questions. S3:B:3, from Spain, for instance, said:

Although it's more realistic, I think I learn more by traditional methods because I see it more clear when I read a paper than a tablet, and I take in more information.

Though some students did not seem to be entirely aware of the reasons why a paper-based task had caused them to have a superior perceived value to their language learning, as evidenced by the "I can't really say why but it does work better than using electronic device for me" comment by S1:A1:8, responses provided by participants indicate that a significant number of students hold a so-called traditional view of how language teaching should occur, where books and printed handouts have an alleged prestigious status and seem to be perceived as inherently superior to comparable materials presented digitally. Simply put, to some students, a more reliable method of teaching a language would be one in which the tasks proposed require students to use pen, paper, and sheets of paper. Even though all the printed materials students were exposed to in the experiment they participated had been extracted from the Internet, and not from renowned published English Language Teaching textbooks, at least one student from each one of the participating groups expressed that having used printed materials in this study gave them the direct feeling of retaining more vocabulary and actually learning the language, which they do not believe to be conceivable if students are encouraged to use their mobile devices instead. Some of the comments which evidence this view can be found in Table 2:

Table 2. Comments extracted from the student surveys showing students' preference for paper-based tasks

\begin{tabular}{ll}
\hline Student & Comment \\
\hline $\mathrm{S} 4: \mathrm{B}: 1$ & "I prefer to read a text, which is printed as it is more trustful." \\
\hline
\end{tabular}




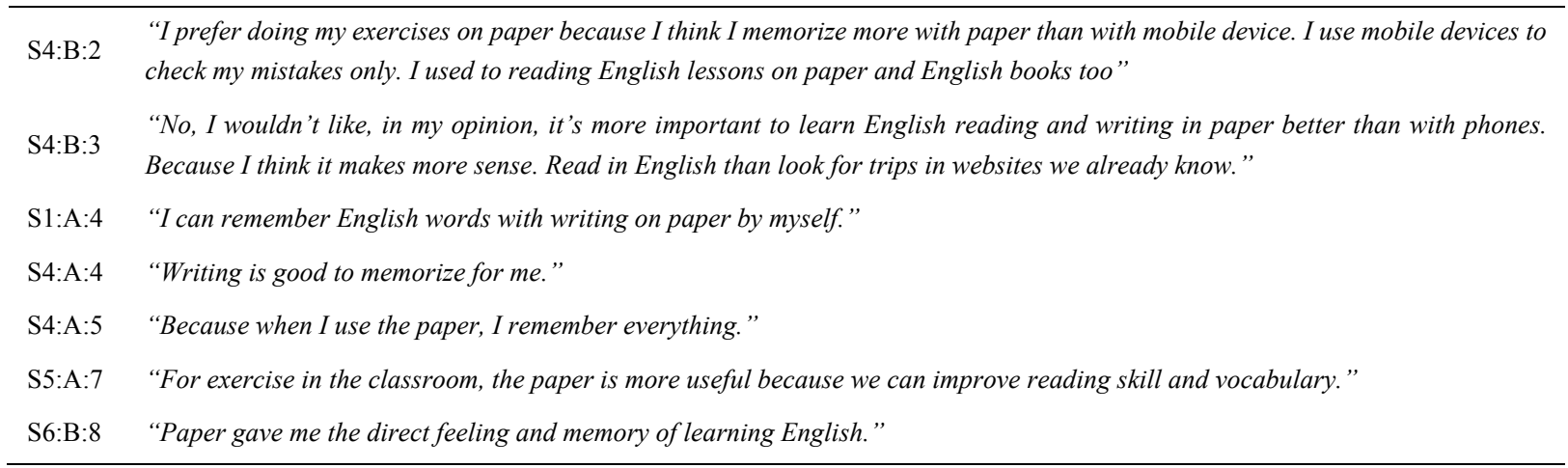

From S4:B:3's comment above, it can be deduced that she would rather use something that attempts to replicate a real-world material rather than using the real-world material itself. It looks as though using a smartphone to access materials directly in their original context, such as the online travel websites as suggested in the experiment, which would chime with the principles of Task-Based Language Teaching and the idea of having learners interact with authentic materials in an authentic way, did not seem to have, at least to some students in the experiment, the same pedagogical value as materials in printed format.

McGrath (2002) highlights that it is possible that learners have "different expectations of classroom activities and their real-world parallels" which might explain why some students find it difficult to make a connection between what a communicative classroom task in a task-based language teaching setting is trying to replicate and achieve, and how this could be linguistically beneficial to them in a real world situation. Surprisingly, such connection seems to have been perceived by the majority of participants in this study. S3:B:2, who said "in real life, I don't get a paper by someone who tell 'yeah, you can choose from here" was among the $70 \%$ of the students who indicated that having used a mobile device to support their language learning made the experimental lesson feel more realistic. In other words, having used a mobile device seems to have given students the impression that they were performing activities that were close to scenarios that they would have encountered in their everyday life, as opposed to the paper-based tasks where students were requested to write a review on a piece of paper to be read by their teachers, or to plan a trip with very limited information available. S2:B:1, who had done the 'planning a trip' task with her smartphone seems to have been able to make this connection appropriately:

It felt like I was learning because it's something I also do at home when I plan a trip but, of course, I do in my own language and not in English and so I learned that I could do this also in another language and that it's not impossible and that you realize that you learn English from doing normal situations in other languages. So this was good, I think.

It is possible that, by asking students to conduct a web-based inquiry learning in this study, in which learners had more control over a great deal of the decision-making process, some uneasiness towards the new and the unknown may have emerged. S4:B:2, from France, for instance, warned that by introducing mobiles to the language classroom, the role of the teacher can become jeopardized. Such concern, which seems to have been shared by a considerable number of the students, along with the prestigious role attributed to printed materials which have been perceived as more reliable, suggests that it is paramount to some individuals that the figure of the teacher be maintained in a power-centric and dominant position in the classroom. S2:A:8, who deems the use of smartphones and tablets in class to be utterly unnecessary, sums up such feeling: "I agree that the Internet make the lesson feel more real, but the teacher can show it on the smartboard. It's no need to use smartphone." Such account suggests that, to S2:A:8, who is from Thailand, a teacher-centered lesson would likely be more pedagogically beneficial to students. S4:A:7, another Asian student, also made reference to the importance of keeping the teacher in control of the lesson, which, as evidenced in her comment below, could be hindered should mobile devices be allowed in the classroom:

\section{If we can use mobiles, the teacher can't control in the class. I think that using mobile will disturb in our study.}

S3:B:2, S5:A:4, S8:B:4, and S8:B:6, conversely, were among the $46.8 \%$ of learners who felt they contributed to their own learning the most in the task where mobile technology had been used. Their comments, available in Table 3, reveal their satisfaction in being in charge of the learning situation: 
Table 3. Students' comments regarding contribution to their own learning

\begin{tabular}{ll}
\hline Student & Comments \\
\hline S3:B:2 & "Because I could use my own ideas." \\
S5:A:4 & "I can search it by myself and see every comments." \\
S8:B:4 & "It makes us to search on our own and could share with everyone." \\
S8:B:6 & "This is because I can make sure about what I would like to see and read. I can choose what I want."
\end{tabular}

Conversely, responses to the open-ended questions provided by twelve students show that, to them, using mobile devices in class equals to having a pocket dictionary for quick reference when needed. Without realizing that a smartphone is "a small device in [one's] pocket [that] can be used like a computer connected to the Internet", as shrewdly noted by S2:A:4, from South Korea, students like S1:A:3 who said: "I prefer studying using books and sheets and using electronic devices only as dictionary", seem to disregard the myriad of possibilities one could exploit when using mobile technology for purposes other than merely looking up words.

In addition to disapproving the redistribution of power in the classroom that might occur if students are allowed to use their portable devices to support their language learning, eleven participants in this study declared they would rather not use smartphones in the language classroom for a number of distraction-related reasons, such as students feeling tempted to check unrelated websites and social media networks, learners losing focus and interest, lessons risking deviating from their original course, and the likelihood of mobile devices hindering oral interaction among learners which, to S5:B:8 in particular, would make going to class illogical. This result is consistent with the findings of Shepperd (2011) on the use of iPads for reading tasks in which oral interaction was reported to have been hindered because of the introduction of mobile technology to the classroom.

Refer to Table 4 for a summary of themes which emerged in participants' answers to open-ended questions:

Table 4. Number of occurrences of each theme identified in answers given to open-ended questions in alphabetical order

\begin{tabular}{ll}
\hline Emerging themes & Number of occurrences \\
\hline Amount of information (overwhelming) & 2 \\
Amount of information (positive) & 16 \\
Authenticity/ Real life applicability & 11 \\
Distraction & 11 \\
Ergonomics & 1 \\
In charge of one's own learning & 4 \\
Negative attitude towards MALL, the task or mobile devices & 6 \\
Positive attitude towards MALL, the task or mobile devices & 27 \\
Self-study & 4 \\
Traditional view of learning & 26 \\
Translation function & 12 \\
Ubiquity & 2 \\
Up-to-dateness & 8 \\
Visual scaffolding & 11 \\
\hline
\end{tabular}

\subsubsection{Demographics-Related Perceptions}

The participating students from South America were the ones who seemed to have enjoyed the MALL tasks the most since all of them demonstrated readiness to use mobile devices in class again in future, whereas the students from Southeast / East Asia were the ones who presented unfavourable arguments towards MALL the most (5 out the 11 participants who presented distraction-related arguments against the use of mobile devices in 
class were from East/Southeast Asia). Similarly, $62.5 \%$ of the participants who reported having preferred the paper-based tasks over the MALL tasks were from Asian. This could be either because they formed the largest cohort of students in this investigation, or because culturally-formed notions of classroom power relations have come into play. In Japan, for example, as noted by Kasuya (2008), students are expected to obey teachers submissively. Though overgeneralizations can often be stereotypical and therefore inaccurate, culturally determined classroom power relations might, in turn, explain why such a relatively high percentage of the participating students from East/Southeast Asia presented arguments opposing the incorporation of mobiles in class. Notwithstanding, $70.6 \%$ of all the Asian students indicated having preferred the MALL tasks over the paper-based ones.

\section{Summary and Final Remarks}

The present study sought to investigate English language learners' perceptions of mobile assisted language learning. Learners were first exposed to both a mobile assisted and an unassisted language learning experience, and then asked to express their thoughts on the incorporation of mobile devices into the language classroom. The mobile assisted tasks involved learners posting a review online based on a real past experience, as well as using web-search engines to gather enough information to plan a hypothetical trip.

The results of descriptive analyses revealed that though students' perceptions were overall positive, a significant amount of scepticism towards MALL emerged. Most of the students indicated that they felt that they had contributed to their language learning the most when the information was provided on paper rather than on mobile devices. As pointed out by Rogers (in: Ushioda 2013), "people bring different degrees of motivation or readiness to embrace new technologies" (p.1). Distraction-related issues and redistribution of power were some of the arguments against the incorporation of mobile devices into the language classroom. Since the most conservative views of mobile assisted language learning were expressed by students from East/Southeast Asia, we can speculate that culturally determined classroom power relations might have played a significant role in influencing how students viewed the use of mobile technology in class.

A number of participants argued that using the Internet from their devices had allowed them to benefit from visual scaffolding whilst others emphasized that having the input and the class resources presented to them on paper rather than on their mobile devices had afforded them a sense of trust. This finding suggests that the format of presentation, rather than the type of task, seemed to constitute a motivational factor that played a psychologically significant role to some of the learners, especially when we consider that the materials used for both paper-based and MALL tasks had been extracted from the same online sources. Student responses indicated that individual preferences and, possibly, learning styles, should be taken into account accordingly when it comes to introducing mobile technology to educational settings. However, when necessary, teachers should help their students expand their learning preferences (APA, 1997) by showing them some of the pedagogical potentialities of mobile technology in language learning, as suggested by Demouy and Kukulska-Hulme (2010).

To other participants, having favoured the use of mobile devices in class related to the higher amount of information online they could have access to, and the supposedly superior quality of the materials, which was attributed to their up-to-dateness. It is worth mentioning that in order to spare students from having feelings of overwhelmingness when required to exploit the virtually infinite array of web-resources available, students should be provided with appropriate guidance in terms of how to navigate knowledge accordingly.

Interestingly, although most of the students were not used to reviewing products and services online, the level of acceptance of the task was still surprisingly high considering that most of the students recognized that having used a mobile device to perform such tasks made the lesson more realistic.

It was observed that the incorporation of a MALL task with an audience beyond immediate peers and tutors seemed to have been slightly less accepted by learners in this experiment. Though not openly expressed by the participants, it is important to bear in mind that having students share their ideas with unknown Internet users can be a highly challenging undertaking for learners to be subjected to. Affective filter levels might be raised if some learners understandably feel intimidated to have their second language output exposed to such a vast audience. Tasks as the ones presented in this experiment should therefore be pre-agreed before being introduced to the language classroom.

\section{Acknowledgments}

I am immensely grateful to Dr. Martin Edwardes for his comments on an earlier version of the manuscript, although any errors found here are my own and should not tarnish his reputation. I would also like to express my sincere gratitude to all individuals who agreed to participate in my study. 


\section{References}

Ally, M. (2013). Mobile learning: from research to practice to Impact Education. Learning and Teaching in Higher Education: Gulf Perspectives, 10(2), 1-10. http://dx.doi.org/10.18538/lthe.v10.n2.140

APA. (1997). Learner-centered psychological principles: A framework for school redesign and reform Retrieved 06/07/2015, from https://www.apa.org/ed/governance/bea/learner-centered.pdf

Badger, R., \& MacDonald, M. (2010). Making it real: Authenticity, process and pedagogy. Applied linguistics, 1-6. http://dx.doi.org/10.1093/applin/amq021

Bahrani, T., \& Shu Sim, T. (2013). Authentic Language Input for Language Learning in EFL/ESL Contexts. International Journal of Language Learning and Applied Linguistics World, 67-73.

Bonk, C. J., \& Cummings, J. A. (1998). A Dozen Recommendations for Placing the Student at the Centre of Web Based Learning. Educational Media International, $25(2), 89$. http://dx.doi.org/10.1080/0952398980350205

Brown, T. H. (2006). Beyond constructivism: navigationism in the knowledge era. On the Horizon, 14(3), 108-120. http://dx.doi.org/10.1108/10748120610690681

Burston, J. (2011). Exploiting the pedagogical potential of MALL. Paper presented at the Mobile Learning as the future of education, San Sebastián, Spain. https://www.researchgate.net/publication/258962305_Exploiting_the_pedagogical_potential_of_MALL

Burston, J. (2014). MALL: the pedagogical challenges. Computer Assisted Language Learning, 27(4), $344-357$. http://dx.doi.org/10.1080/09588221.2014.914539

Carrell, P. L. (1983). Some issues in studying the role of schemata, or background knowledge, in second language comprehension. Paper presented at the TESOL Convention, Toronto, Ontario.

Chen, J. C., \& Brown, K. L. (2012). The effects of authentic audience on English as a second language (ESL) writers: A task-based, computer-mediated approach. Computer Assisted Language Learning, 25(5), 435-454. http://dx.doi.org/10.1080/09588221.2011.606224

Chinnery, G. M. (2009). Emerging Technologies: Going to the MALL Retrieved 05/06/2015, from http://lt.msu.edu/vol10num1/emerging/

Comas-Quinn, A., Mardomingo, R., \& Valentine, C. (2009). Mobile blogs in language learning: making the most of informal and situated learning opportunities. ReCALL, 21(01), 96-112. http://dx.doi.org/http://dx.doi.org/10.1017/S0958344009000032

Demouy, V., \& Kukulska - Hulme, A. (2010). On the spot: Using mobile devices for listening and speaking practice on a French language programme. Open Learning, 25(3), $217-232$. http://dx.doi.org/10.1080/02680513.2010.511955

Elias, T. (2011). Universal instructional design principles for mobile learning. The International Review of Research in Open and Distributed Learning, 12(2), 143-156.

Fotouhi-Ghazvini, F., Earnshaw, R. A., \& Haji-Esmaeili, L. (2009). Mobile assisted language learning in a developing country context. CyberWorlds, $2009 . \quad$ CW'09, 391-397. http://dx.doi.org/http://dx.doi.org/10.1109/CW.2009.28

Gallien, C. (1998). Cultivating the authentic: Past, present and future of authentic documents. Forum for Modern Language Studies, 34(2), 156-169. http://dx.doi.org/10.1093/fmls/XXXIV.2.156

Garcia, I. (2013). Learning a Language for Free While Translating the Web. Does Duolingo Work? International Journal of English Linguistics, 3(1), 19. http://dx.doi.org/http://dx.doi.org/10.5539/ijel.v3n1p19

Godwin-Jones, R. (2011). Emerging technologies: Mobile apps for language learning. Language Learning \& Technology, 15(2), 2-11.

Guariento, W., \& Morley, J. (2001). Text and task authenticity in the EFL classroom. ELT Journal, 55(4), 347-353. http://dx.doi.org/10.1093/elt/55.4.347

Herrington, A., \& Herrington, J. (2007). Authentic mobile learning in higher education. Paper presented at the Australian Association for Research in Education (AARE) International Educational Research Conference Australila.

Kasuya, M. (2008). Classroom interaction affected by power distance. Language Teaching Methodology and 
Classroom Research and Research Methods.

Khazaie, S., \& Ketabi, S. (2011). Contribution to vocabulary learning via mobiles. English Language Teaching, 4(1), 174-184. http://dx.doi.org/10.5539/elt.v4n1p174

Kim, D., Rueckert, D., Kim, D.-J., \& Seo, D. (2013). Students' perceptions and experiences of mobile learning. Language, Learning \& Technology, 17(3), 52.

Koole, M. L. (2009). A model for framing mobile learning. In M. Ally (Ed.), Mobile learning: Transforming the delivery of education and training (Vol. 1, pp. 25-47). Edmonton, Canada: Athabasca University Press.

Kukulska-Hulme, A. (2009). Will mobile learning change language learning? ReCALL, 21(02), 157-165. http://dx.doi.org/10.1017/S0958344009000202

Kukulska-Hulme, A., Norris, L., \& Donohue, J. (2015). Mobile pedagogy for English language teaching: a guide for teachers.

Kukulska-Hulme, A., \& Shield, L. (2007). Can Mobile Devices Support Collaborative Practice in Speaking and Listening. ReCALL, 271-289. http://dx.doi.org/10.1017/S0958344008000335

Lacina, J. (2008). Technology in the classroom: learning English with iPods. Childhood Education, 84(4), 247-249. http://dx.doi.org/10.1080/00094056.2008.10523019

Lai, C., \& Li, G. (2013). Technology and task-based language teaching: A critical review. CALICO journal, 28(2), 498-521. http://dx.doi.org/10.1558/cj.v28i2.498-521

Martin, F., \& Ertzberger, J. (2013). Here and now mobile learning: An experimental study on the use of mobile technology. Computers \& Education, 68, 76-85. http://dx.doi.org/10.1016/j.compedu.2013.04.021

McCloskey, M. L. (2005). Visual scaffolding to support ell reading. Keeping the Promise, 1-7.

McGrath, I. (2002). Using the real Materials evaluation and design for language teaching (pp. 101-138). Edinburgh, UK: Edinburgh University Press.

Miangah, T. M., \& Nezarat, A. (2012). Mobile-assisted language learning. International Journal of Distributed and Parallel Systems, 3(1), 309-319. http://dx.doi.org/10.5121/ijdps.2012.3126

Nunan, D. (1989). Designing tasks for the communicative classroom: Cambridge University Press.

Nunan, D. (1999). Second Language Teaching \& Learning: ERIC.

Peacock, M. (1997). The effect of authentic materials on the motivation of EFL learners. ELT Journal, 51(2), 144-156. http://dx.doi.org/10.1093/elt/51.2.144

Petersen, S. A., Divitini, M., \& Chabert, G. (2009). Sense of community among mobile language learners: can blogs support this? International Journal of Web Based Communities, 5(3), 428-445. http://dx.doi.org/10.1504/IJWBC.2009.025217

Sheppard, D. (2011). Reading with iPads-the difference makes a difference. Education Today, 3(2011), 12-17.

Shneiderman, B. (1998). Relate-Create-Donate: a teaching/learning philosophy for the cyber-generation. Computers \& Education, 31(1), 25-39. http://dx.doi.org/http://dx.doi.org/10.1016/S0360-1315(98)00014-1

Skehan, P. (1996). A framework for the implementation of task-based instruction. Applied linguistics, 17(1), 38-62. http://dx.doi.org/10.1093/applin/17.1.63

Stockwell, G. (2007). Vocabulary on the move: Investigating an intelligent mobile phone-based vocabulary tutor. Computer Assisted Language Learning, 20(4), 365-383. http://dx.doi.org/10.1080/09588220701745817

Stoks, G. (2002). WebQuest: Task-based learning in a digital environment. Babylonia, 1, 56-58.

Sussex, R. (2012). Text input and editing as a bottleneck in mobile devices for language learning. Computer-enhanced and mobile-assisted language learning, 220-234. http://dx.doi.org/http://dx.doi.org/10.4018/978-1-61350-065-1.ch011

Trifonova, A., Knapp, J., Ronchetti, M., \& Gamper, J. (2004). Mobile ELDIT: Challenges in the Transition from an e-Learning to an m-Learning System.

Ushioda, E. (2013). Motivation matters in mobile language learning: A brief commentary. Language Learning \& Technology, 17(3), 1-5.

Warschauer, M., \& Whittaker, P. F. (1997). The Internet for English teaching: Guidelines for teachers. TESL Reporter, 30(1), 27-33. 
Woodcock, B., Middleton, A., \& Nortcliffe, A. (2012). Considering the Smartphone Learner: an investigation into student interest in the use of personal technology to enhance their learning. Student Engagement and Experience Journal, 1(1), 1-15. http://dx.doi.org/10.7190/seej.v1i1.38

Zilber, J. (2013). Smartphone apps for ESL: Finding the wheat amidst the chaff. Contact Magazine, 39, 15-21.

\section{Appendix}

TASK $1 B$ - MOBILE UNASSISTED TASK

\section{STAYING AT A HOTEL}

SHARING YOUR EXPERIENCES

01 - In pairs, talk about a memorable hotel you have stayed in.

- Where in the world is this hotel?

- What kind of services, facilities and amenities were available? What was the overall service like? Was it located conveniently? Was your stay memorable because of a positive or negative experience you've had?

- Would you recommend this place to anyone?

Provide your partner with as many details as possible.

02 - Read the reviews provided posted on TripAdvisor by guests who stayed in a hotel in London. Are their experiences any similar to yours?

Share with your partner the opinions that were most similar or most divergent to the experience you had during your stay.

03 - Write a review (80 to 100 words) based on the experience you had during your stay at the hotel you talked about. What do you think prospective guests should know about this hotel? If you had a negative experience, it might be a good idea to write about something you would have liked to know prior to your stay. Express your thoughts on the service provided honestly. 


\section{VACATION TIME!}

PLANNING A HOUDAY TRIP!

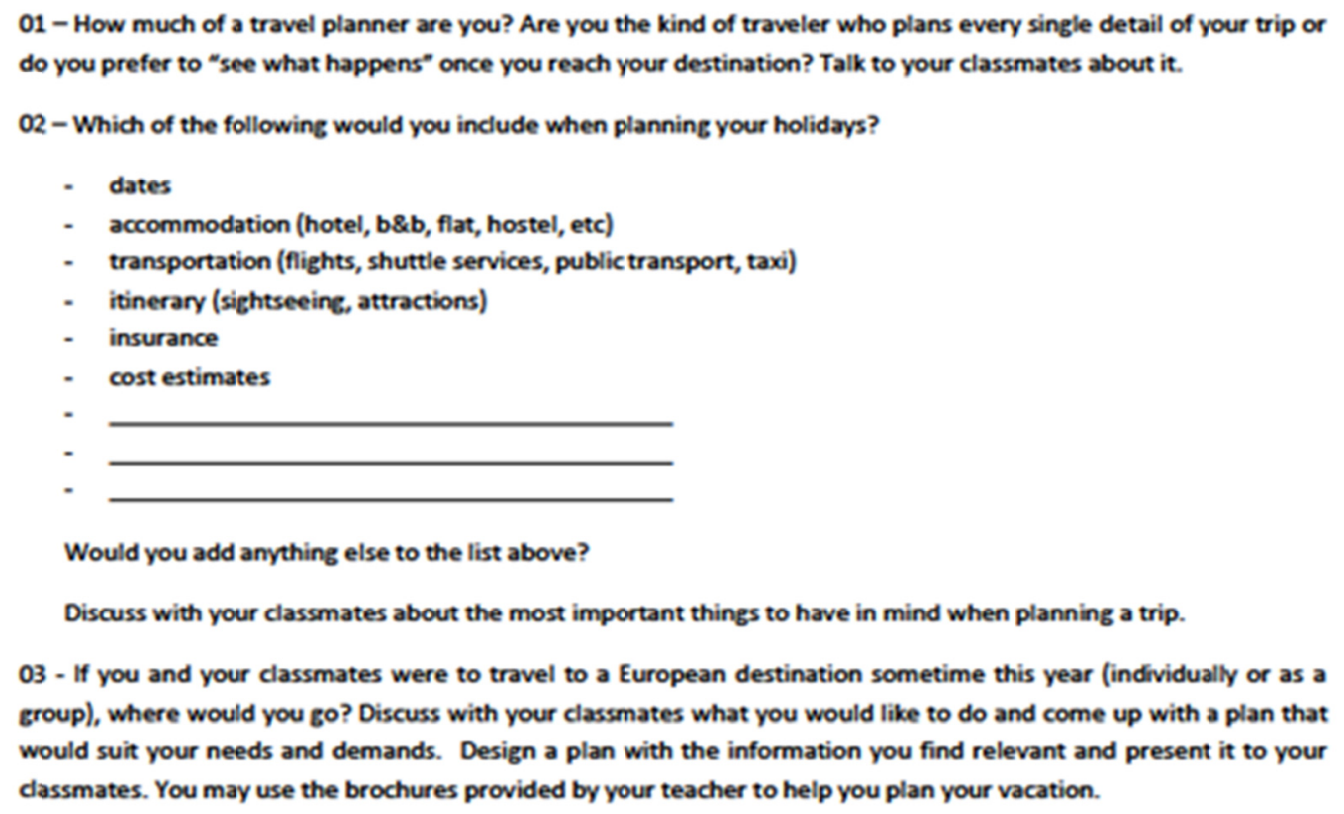

$\cdot$

$-$

Would you add anything else to the list above?

Discuss with your classmates about the most important things to have in mind when planning a trip.

03 - If you and your classmates were to travel to a European destination sometime this year (individually or as a group), where would you go? Discuss with your classmates what you would like to do and come up with a plan that would suit your needs and demands. Design a plan with the information you find relevant and present it to your classmates. You may use the brochures provided by your teacher to help you plan your vacation.

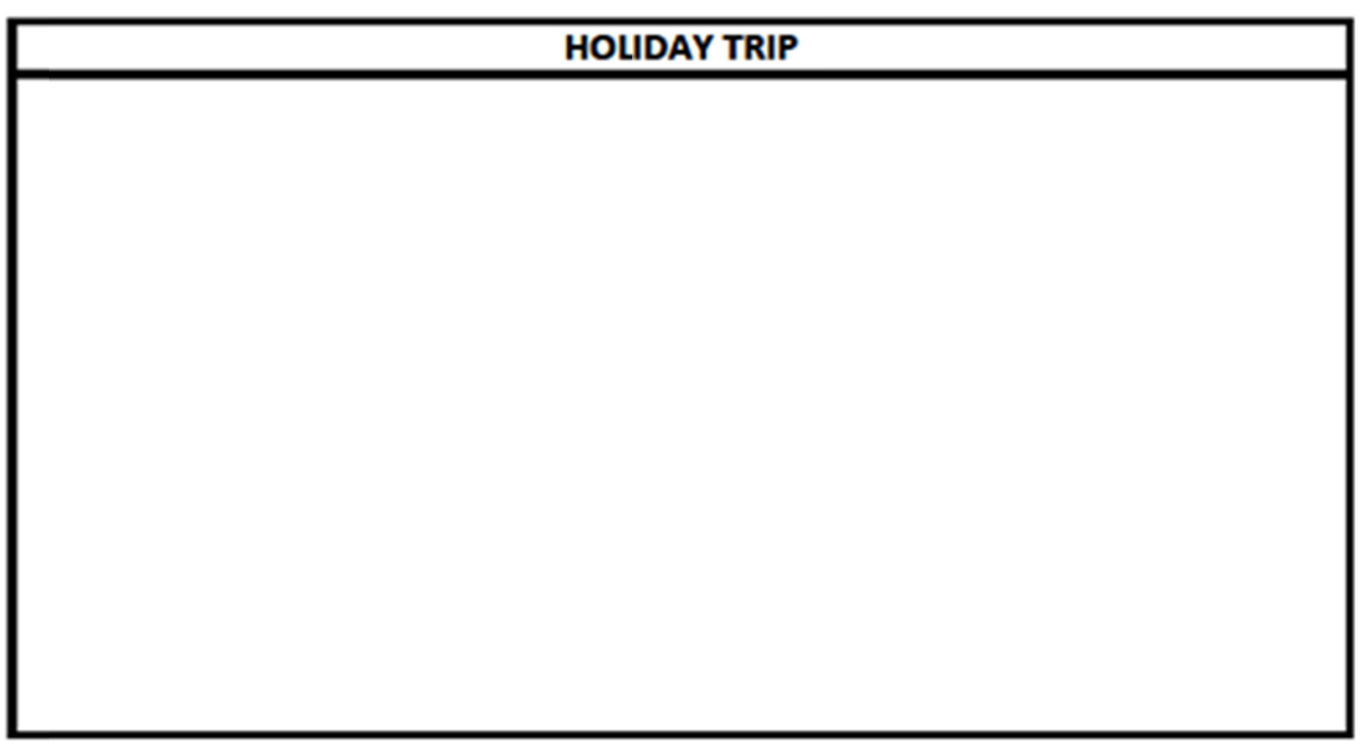

\section{Copyrights}

Copyright for this article is retained by the author(s), with first publication rights granted to the journal.

This is an open-access article distributed under the terms and conditions of the Creative Commons Attribution license (http://creativecommons.org/licenses/by/4.0/). 